\title{
Os alfabetizados-desviantes ou sobre a educação dos 6 anos'
}

Leni Vieira Dornelles

Universidade Federal do Rio Grande do Sul
Correspondência:

Leni Vieira Dornelles

Av. Loureiro da Silva, $n^{\circ}$ 1500/812

90050-240 - Porto Alegre - RS

E-mail: ledornel@redemeta.com.br

1. Pretendo neste artigo homenagear a professora que comigo ousou produzir crianças leitoras e escritoras sem ser fiel às cartilhas e, por isso, foi punida e expulsa da sala de aula do primeiro ano de 6 anos. À minha professora de Jardim de Infância I da Paupério, que permitiu que a alegria permeasse as descobertas de nossa sala de aula aos 6 anos.

\section{Resumo}

Neste texto, busca-se fazer emergir a análise realizada numa classe de primeiro ano de 6 anos do ensino fundamental de nove anos de uma escola pública de periferia de Porto Alegre (RS). Ele indica como as crianças deste primeiro ano tramam seu processo de alfabetização e escapam do estigma da tristeza e do fracasso. Estudam-se os documentos (MEC- Lei no. 11. 274, de 2006 /EFNA) que ordenam e administram a vida de crianças e professores, através de programas empresariais e governamentais, e se tornam o olho Argos Panopticon. Optando-se por uma metodologia-bricolagem e baseando-se nos estudos pós-estruturalistas, trama-se a análise dos documentos legais com observações participantes. Mostra-se um acontecimento especial que marcou a alfabetização desta turma ou sobre como, a partir de Flávia, a menina que ajuda a pensar o título deste artigo, de 6 anos, guria, preta, gorda e que, portanto, fugia de todos os parâmetros da naturalização dos sujeitos-meninas ou daqueles que têm tudo para dar certo na vida, encontra um modo de se alfabetizar e com ela o seu grupo. Trata-se da alegria na sua potência de agir de uma alfabetizanda-desviante ao se constituir como leitora de histórias para seu grupo, e como esta vitalidade de criação transforma o aprendizado de crianças e professores. Encerra-se o artigo com o desejo de que se faça emergir a alegria spinoziana da descoberta da alfabetização, mesmo que desviante, no processo de meninas e meninos alfabetizandos com 6 anos. Convida-se ao desvio!

\section{Palavras-chave}

Alfabetização aos 6 anos - Biopolítica - Alfabetizandosdesviantes - Brincar - Ensino de nove anos. 


\section{The deviant-literates, or on the education at the age of six'}

Leni Vieira Dornelles

Federal University of Rio Grande do Sul

Contact:

Leni Vieira Dornelles

Av. Loureiro da Silva, $n^{\circ}$ 1500/812

90050-240 - Porto Alegre - RS

E-mail: ledornel@redemeta.com.br

1. With this article I want to pay a tribute to the teacher who, along with me, dared to create reading and writing children without being faithful to the primers, and for that was punished and expelled from a six-year-olds classroom. To my first year teacher at the Paupério daycare center, who allowed joy to pervade the discoveries of our six-year-olds class.

\begin{abstract}
In the present text we bring forward the study carried out with a first-year class of six-year-olds from a nine-year fundamental schooling public unit located at the outskirts of Porto Alegre, Rio Grande do Sul. It reveals how the children from this first-year class weave their literacy process, and escape from the stigma of sorrow and failure. We analyze the documents that order and organize the life of children and teachers (MEC Law No. 11274 of 2006 and EFNA) through business and governmental programs, which thereby become the all-seeing eye - Argos Panopticon. Opting for a handicraft methodology, and based on poststructuralist studies, we interlace the analysis of legal documents with participant observations. A special situation is described here that left its mark on the literacy process of this class, namely, how Flávia, the chubby Black six-year-old girl that helps giving title to this article, firmly outside every naturalizing parameter of girl-subjects, or of those who have everything going for them in life, finds her own way to learn to read, and takes her group with her. One deals here with the joy, in its power to act, of a deviantliterate who constitutes herself as a reader of stories to her group, and how this vitality of creation transforms the learning process of children and teachers alike. The article concludes wishing that we evoke the Spinozian joy of the discovery of literacy, even if deviant, in the literacy process of six-year-old boys and girls. An invitation to deviate!
\end{abstract}

\section{Keywords}

Literacy of six-year-olds - Biopolitics - Deviant-literates Playing - Nine-year schooling. 
A criança apela à incerta alfabetização do mesmo modo que o aprender não se esgota no resultado do aprendido nem a chegar a saber o já sabido. É-se criança no movimento de aprender, no balbuciar da língua [...]. (Jódar, Gómez, 2002, p. 41)

Pensar sobre como as crianças se alfabetizam aos 6 anos é o desejo do presente artigo. Ele trata de discutir a produção de crianças leitoras e produtoras de texto no ensino fundamental de nove anos. Faz parte da pesquisa realizada em uma escola da rede pública da periferia de Porto Alegre, Rio Grande do Sul, numa turma de 6 anos. Busca pensar a alfabetização das crianças com o olhar de uma professora que, por sua formação e experiência com educação infantil, foi convidada a exercer sua docência com crianças que iriam para o "novo" primeiro ano.

Os meninos e meninas que faziam parte dessa sala de aula frequentavam também outras instituições que não apenas a escola e a família. Eram crianças que viviam seu cotidiano além dos muros da escola em casas de cuidadores, em casas vigiadas pelos irmãos ou sob a tutela de parentes e amigos. Crianças que, para não "ficarem tão sozinhas", assistiam à TV em casa ou na casa de vizinhos, brincavam e cuidavam dos irmãos menores. Faziam tarefas de casa, iam ao armazém. Muitas delas assistiam, no seu cotidiano, a cenas de delito, drogadição, tráfico, prisões, quem sabe serviam também como aviãozinho para os traficantes da vila.

A partir da cena apresentada, pode-se entender o desejo de muitos pais de que seus filhos ficassem o máximo de tempo possível sob a tutela da escola. Eles viam na escola, na alfabetização de seus filhos, uma possibilidade de redenção. Sobre isto, afırmavam:

Quero que ele estude para o futuro. Hoje em dia tá difícil pegá um serviço sem sabê lê. Até de doméstica, se tem que dá um remédio tem que sabê. Se qué sê uma mulhé independente, não dependendo do marido, tem que sabê. Não é futuro pra ninguém ficá de empregada, principalmente a minha filha que qué ficá toda arrumada. (Cf. mãe de aluno)
Este excerto apresenta a expectativa de saída e libertação para uma vida "melhor" por meio da educação. Isso faz com que muitos pais depositem na escola a única possibilidade de escapar da vida árdua da periferia e de algumas pessoas que habitam as vilas de nossas cidades.

Pretendo com isto mostrar que, quem sabe, não são estas as crianças alfabetizadas-desviantes que, mesmo com todas as suas mazelas, se constituem como leitores e escritores? Como os alfabetizandos-desviantes, ou as crianças do primeiro ano de uma escola de periferia de Porto Alegre como qualquer outra deste país, tramam seu processo de alfabetização e escapam do estigma do fracasso, é o que desejo ao trazer esta experiência de trabalho com crianças de 6 anos.

\section{Por uma biopolítica de governo: alfabetização e letramento}

Busco a legislação que sustenta ou que se diz organizada para amparar a qualidade de interações frente à aprendizagem das crianças. Trago, então, parte do discurso oficial do país, quando de sua exigência e reorientação legal sobre a educação. 0 parecer do Ministério de Educação, do ano 2007, formula as diretrizes específicas e orientações para a inclusão da criança de 6 anos no ensino fundamental de nove anos (EFNA). É esse efeito de ordenamento que em todas as esferas se impõe sob o pretexto de desenvolver o bem-estar da população, no caso a infantil, que Foucault chamou de biopoder, que se revela como estratégia cuja finalidade é o aumento da ordem e do próprio poder. 0 poder sobre a vida das crianças e, consequentemente, de professores.

Volto ao documento intitulado o "Ensino fundamental de nove anos - orientações para a inclusão da criança de seis anos de idade - Primeiro ano é fundamental", quando aponta para uma direção propositiva baseada na lei $n^{\circ}$. 11 . 274 de 2006, que institui o ensino fundamental de nove anos de duração. Tal documento apresenta uma discussão sobre a infância, o brincar, as diversas expressões, o desenvolvimento, o 
letramento e a avaliação. Problematiza-se tal documento, entendendo-o como uma prática discursiva, e compartilho com Fischer (2001), quando se refere às práticas discursivas em Foucault (2000), afirmando que "tudo é prática em Foucault [...] enunciados e visibilidades, textos e instituições, falar e ver constituem práticas sociais por definição permanentemente presas, amarradas às relações de poder, que as supõem e as atualizam" (p. 200).

Foucault (2000) escreve que "as palavras nos enganam e nos fazem acreditar na existência das coisas" (p. 252), que as palavras enganam por representarem diferentes coisas em diferentes contingências e práticas. Que práticas discursivas emergem dos documentos que tratam do ensino fundamental de nove anos e como estas se relacionam às políticas da alfabetização, à evasão e à permanência das crianças de 6 anos na escola?

Também como práticas discursivas, emergem as orientações do Ministério da Educação (MEC), quando, no capítulo de sua introdução, indica que as escolas e os professores precisam atentar para que a alfabetização das crianças de 6 anos aconteça em dois anos e que não se deve restringir as aprendizagens e nem "restringir a aprendizagem das crianças de seis anos de idade à exclusividade da alfabetização no primeiro ano do ensino fundamental de nove anos" (Beauchamp, Pagel, Nascimento, 2007, p. 9).

Ao mesmo tempo, o documento utiliza como justificativa para a inserção das crianças no primeiro ano ou nas classes de alfabetização e de letramento a afırmação de que a ampliação do ensino fundamental de nove anos "significa, também, uma possibilidade de qualificação do ensino e da aprendizagem da alfabetização e do letramento". São essas as direções do MEC para o ensino de primeiro ano. Portanto, tal documento representa as ideias, as orientações, a postura teórica e metodológica do Ministério no que tange à alfabetização e ao letramento das crianças no Brasil.

Estes dois documentos, de algum modo, norteiam a organização das propostas pedagógi- cas nos estados, o que pode ser constatado, por exemplo, na Proposta Pedagógica de Alfabetização do Estado do Rio Grande do Sul do GEEMPA, nos propósitos da Alfa e Beto e na Fundação Airton Senna. Contudo, questiona-se como funcionam tais documentos nas classes de alfabetização do Brasil. 0 que acontece com os professores que continuam ensinando a seu modo e sem seguir as ordens das empresas selecionadas para dar o suporte material (pedagógico) para tais classes? Como são avaliados os professores que não exigem que a criança preencha três páginas diárias de suas cartilhas?

Tais prerrogativas compõem as políticas públicas destinadas a regular o ensino fundamental de nove anos (EFNA), surgido num momento de ruptura da educação dos infantis de 6 anos ou da educação até aqui produzida para eles. Ou seja, infere-se que tais documentos pretendem gerir a educação da população infantil quanto ao aspecto teórico, didático-pedagógico, metodológico e de técnicas de alfabetização para esta parcela da população infantil. Resta-nos ainda investigar os efeitos de tais documentos no cotidiano das classes de 6 anos, trabalho em parte já realizado na dissertação de mestrado de Rochele da Silva Santaiana (2008), intitulada +1 ano é fundamental: práticas de governamento dos sujeitos infantis nos discursos do ensino fundamental de nove anos. Nesta, a autora investiga a justificativa para a criação desse modo de educação, mostrando como tal demanda advém de uma racionalidade política por ela postulada; atenta para qual o atravessamento econômico e social que perpassa a biopolítica do alfabetismo e letramento aos 6 anos e como esse modo de educação é uma medida de solução social.

Alguns autores justificam a inserção das crianças no primeiro ano afırmando que esta ação colabora para se diminuir o surgimento de riscos sociais. Talvez ali, bem ali, onde está o perigo, ali mesmo cresça também aquilo que possa nos liberar e, desse modo, policiar, vigiar, controlar se transformem na possibilidade de nos "salvar" (Hölderlin, 1991), ou melhorar a educação das crianças e da população infantil, tal como "sonham" seus 
pais, como me referi anteriormente. Sobre risco, Riffel (2005) dá-nos um exemplo: "em todas as situações, os indivíduos considerados de 'alto risco' são destacados como indivíduos que necessitam de orientação especializada, investigação e controle ou autocontrole" (p. 60). Assim, de algum modo, as crianças, na justificativa destes documentos, precisam serem governadas. Pergunto: será que as crianças estavam mal governadas nas escolas de educação infantil e precisaram, com isso, ser enviadas para o primeiro ano com 6 anos ou esta foi uma estratégia de governamentalidade sobre elas? Ainda sobre risco, é interessante o que discute Spink, (2000), ao tratar dos contornos do risco na modernidade reflexiva e das contribuições da psicologia social sobre eles; a autora discute ainda a quem compete legislar sobre estes nas diferentes esferas humanas.

É necessário fazer a análise de tais práticas com o propósito de desnaturalizá-las, desconstruí-las e ver o que aparece como "natural" na proposta dos documentos. Desnaturalizar no sentido guattariano de pensar diferente daquilo que se pensava sobre o que está acontecendo nas salas de aula no primeiro ano, quando grupos e empresas, em nome do "bom governo das crianças", se propõem a reinventar "novas" práticas de alfabetização nos estados. Essas são formas que o Estado encontra de exercer o governo da população infantil através de práticas sociais e escolares diversificadas, ao que Foucault denomina de dispositivo de poder. Santaiana (2008), acuradamente, afirma que, através dessa prerrogativa, o MEC pretende inventar “ uma racionalidade política que visa à abrangência nacional, mas que também procura exercer o governamento de cada sujeito infantil a que se destina, (...) através de prescrições sobre como deve ser o ensino e a aprendizagem da criança de seis anos" (p. 43-44).

Tal documento produz diferentes saberes com a intenção de orientar o trabalho pedagógico, as atividades escolares para as crianças de 6 anos, que agora passam a ser escolares e não mais pré-escolares. Passam a ser educadas através do livro didático que pretende orientar os sistemas de ensino a melhor conduzirem seus aprendizes de 6 anos. Assim, ele refere:

Entrando mais cedo na escola, as chances de sucesso na trajetória escolar serão maiores. Um passo importante para a diminuição das desigualdades sociais no país. [...] A iniciativa visa elevar a escolaridade das crianças, especialmente daquelas sem acesso à educação infantil, e levar mais cedo para a escola as que estão em situação de risco social. (Cadernos do MEC, junho de 2006, p. 4)

Esta garantia visa incluir imediatamente as crianças com 6 anos e, para dar conta disso, o Ministério construiu orientações elaboradas por especialistas para os sistemas. Tal normativa é apresentada em nove capítulos de seu "manual" de orientações. Neste documento, as escolas terão informações relevantes para o atendimento "adequado" aos estudantes.

Contudo, a Constituição 1988, ao afirmar que é dever do Estado garantir a educação efetivada da criança - art. 208: IV "atendimento em creche e pré-escola às crianças de zero a seis anos de idade" -, modifica seu discurso e passa a inventar novas verdades, que sustentem a governamentalidade das crianças de 6 anos. Muda-se o discurso e mostra-se a partir daí a provisoriedade das verdades acerca dos infantis.

0 que se pode apreender de tudo isso é que, como já afirmei em outro lugar, analisar a infância significa, então, conjurar a ilusão de sua origem e mostrar suas transformações, demarcar seus momentos de força e fraqueza, suas alternâncias, apreendendo também seus diferentes momentos históricos (Foucault, 2000). Se as biopolíticas engendradas para o governo das crianças estão comprometidas com a produção de verdades, então, consequentemente, tal política de verdade deve ser conhecida e desnaturalizada.

Trago o estudo de Suzana Schineider (2009), intitulado 0 projeto-piloto de alfabetização do Rio Grande do Sul: um olhar de estranhamento sobre seus materiais didáticos, 
em que ela discute que o que parece tão natural em algumas propostas de alfabetização aos 6 anos não deixa de compor modos de educação de um projeto que se diz libertário, mas que, paradoxalmente, se sustenta em princípios da sujeição. Assim, ela se questiona: como tais documentos, tais prerrogativas legais educam para a liberdade a partir da sujeição?

A análise de Schineider mostra como os discursos do GEEMPA - entendo que também das outras empresas que propõem alfabetização a partir do novo ordenamento legal, como Alfa e Beto e Senna - são atravessados por discursos de letramento, construtivismo, psicogênese, antropologia social, das metodologias de alfabetização desde 0 teste $\mathrm{ABC}$ etc., que estão fortemente associados a uma racionalidade mais ampla de governamentalidade. Ou seja, como as crianças e os professores estão a eles afetos como parte de uma população que precisa ser medida através de desempenhos avaliativos, ser calculada para que faça parte de uma estatística de aprovação e sucesso, categorizada em níveis (do pré-silábico ao silábico); exigem sua descrição minuciosa e esquadrinham com fins avaliativos quanto ao seu planejamento, preenchimento de fichas e dados; ordenam-se em séries e níveis as "escadas" do aprender, não só para fazer parte de uma estatística, mas também para avaliar tal saber em busca da normalização de uma infância alfabetizada. Isso nos lembra aquilo a que Nietzsche se refere: "o conhecimento esquematiza, ignora as diferenças, estimula as coisas entre si, e isto sem nenhum fundamento em verdade" (Foucault, 1999, p. 25).

A partir do exposto, pode-se dizer que, hoje, o governo das crianças passa pela demarcação de um significado de infância, pelos processos de individuação e objetivação, por sua institucionalização e escolarização, a partir dos regimes de verdade instituídos pela sociedade, que, através de uma biopolítica, busca modos de gerenciar sua vida, e aqui fica evidente que isso passa pela necessidade de ingresso e vigilância nos modos de aprender a ler e a escrever cada vez mais precoces na educação das crianças.
Tal gerenciamento sobre a vida das crianças evidencia que esses programas compõem o "grande olho" sobre o processo de alfabetização, ou seja, reedita-se a lenda do pan-óptico, usando-a como metáfora do grande olho pan-óptico que paira sobre crianças e professores - o olho Argos Panopticon. Além de genial narrativa, esta é a metáfora dos modos de vigilância constituídos ao longo da história e, por que não, em nosso tempo, no que se refere à alfabetização e ao letramento das crianças de 6 anos. Entendo, portanto, que tal lenda possa ser reeditada ao se analisar os discursos que perpassam os programas de alfabetismo e letramento do ensino fundamental2 ${ }^{2}$.

\section{Histórias de uma sala de primeiro ano ou sobre uma alfabetizanda-desviante}

Como ensina Foucault, não há poder sem resistência, e foi isso que se encontrou na turma de primeiro ano de 6 anos. Passo, neste momento, a narrar os acontecimentos em uma sala de aula com crianças de 6 anos em uma escola pública na periferia de Porto Alegre, a qual já foi apresentada no início deste trabalho. A professora, como tantas outras deste país, optou por resistir e ficar à margem dos métodos que deveriam garantir a alfabetização das crianças de sua sala. Isso, de algum modo, nos ajuda a problematizar como isso aconteceu nessa classe e o que está acontecendo em muitos primeiros anos de 6 anos. Emerge, atualmente, uma outra preocupação entre professores e pais: qual o conteúdo a ser desenvolvido na faixa etária de 4 anos ou o que se deve tratar como conteúdo, nessas turmas, a fim de que as crianças se preparem para o primeiro ano de 6 anos? Talvez esta seja apenas uma situação pontual da escola pesquisada, tendo em vista que a comunidade conhece o projeto de alfabetização utilizado por ela no primeiro ano do ensino fundamental.

2. Quando este texto estava sendo escrito, o Conselho Nacional de Educação votava uma medida que impede que os alunos repitam 0 ano escolar. Afirma, a notícia: "Entre as justificativas do CNE para que a medida seja implantada está uma estatística de que, em 2009, 80 mil crianças com 6 anos de idade foram reprovadas". Correio do Povo, domingo, 20 de junho de 2010, p. 9. 
Na experiência aqui discutida, no início do ano letivo, muitas crianças não demonstravam nenhum interesse pelos livros que estavam disponíveis na sala de aula dos 6 anos. Penso que isso se devia a dois motivos: os livros não estavam disponibilizados anteriormente para elas pelas professoras; por outro lado, eles não faziam parte do cotidiano de quase todas as crianças naquela sala de aula, o que era observado em muitas conversas com seus pais. Para muitas delas, o máximo de envolvimento com os livros era com os didáticos dos irmãos mais velhos, a Bíblia, alguns gibis, o calendário (folhinha) e, raramente, um jornal popular de grande circulação no estado.

A ordem e guia de experimentação da alfabetização era a de estar sensível às possibilidades das crianças e atravessar com elas a linha de fuga deleuziana, a linha feiticeira, o estigma de que as crianças pobres não se alfabetizam. Para a professora dessa turma, foi necessário cruzar a linha feiticeira de que nos fala Deleuze. Foi preciso que pudesse sair do reconhecível e tranquilizador das verdades apresentadas nas cartilhas e constituir, com aquele grupo de crianças de 6 anos, novas verdades sobre como se alfabetiza nessa faixa etária.

Daí ela se propôs a pensar a proveniência dos questionamentos e problematizações contemporâneas sobre a criança de 6 anos e sua alfabetização. Sua educação, no contexto do que parece ser uma tensão entre, de uma parte, o apagamento das fronteiras etárias e, portanto, a morte, o desaparecimento da infância e, de outra, desconstruir a divisão entre o mundo infantil e o mundo adulto, com a emergência de uma nova forma de infância alfabetizada. Caminharam, professora e pesquisadora, sobre a linha feiticeira, e inventou-se um outro lado do saber, aprendendo de um outro modo como se dão as relações e as produções sobre o alfabetismo e o letramento das crianças. Seguiu-se a sugestão de Deleuze (1992), ou seja, a de que não "cabe temer ou esperar, mas buscar novas armas” (p. 220), e as novas armas eram, como na educação infantil, seguir o mapa traçado com as crianças. Dar continuidade àquilo que se fazia na educação infantil, ou seja, prolife- rar o pensamento e a interação das crianças para com a leitura e a escritura.

Entendia-se que as crianças, tendo em vista a sua realidade (expressa anteriormente), levariam para casa os livros de literatura infantil da escola e, no outro dia, contariam para os colegas a história que leram. Fez-se este movimento de desejar ler o livro mesmo se sabendo que muitas das crianças tinham pais não alfabetizados. Assim, as crianças foram encontrando soluções, e os que quisessem levariam os livros para que um irmão, um vizinho, um primo, alguém lesse o livro para elas.

No início, alguns acontecimentos quase nos levaram a desistir do envio dos livros para casa, mas investimos na ideia e as crianças foram resolvendo os problemas que surgiam, como o de quem iria ler para elas. Foram trazendo de volta os livros da sala e deixando de dizer: "a minha mãe não teve tempo de ler para mim"; "ela chegou cansada e não leu”; "a minha mãe não sabe ler"; "o meu pai chega muito tarde e eu já tô dormindo". Aos poucos elas chegavam contando suas histórias, e proposta inicial foi tendo continuidade: alguém lhes contava as histórias.

Tecendo a rede de nossas memórias com as histórias infantis com o que se tramava na educação infantil, tivemos possibilidade de pensar como os contadores de nossas histórias nos subjetivaram a sermos leitores e ouvidores de muitos contos. Vivemos, na sala de 6 anos, histórias de Flávias, Vânias, Jucelis, Adilsons, Joões (Dornelles, 2010), crianças e professoras que nos ensinam e ensinavam, através de suas memórias de contadoras, a importância de terem sido subjetivadas pelos adultos que com elas conviveram, fossem estes seus pais, professores, bibliotecários ou mesmo amantes dos livros, como o guarda da biblioteca pública da vila. Através das narrativas dos contadores, procurava-se atender ao objetivo de ouvir professoras e crianças acerca de suas vivências em relação à prática da contação de histórias e as estratégias utilizadas por elas com seus alunos.

Pego emprestado, para pensar sobre este trabalho, Diana e Mário Corso (2006), quando assim se referem às histórias: 
Histórias não garantem a felicidade nem o sucesso na vida, mas ajudam.

Elas são como exemplos, metáforas que ilustram diferentes modos de pensar e ver a realidade e, quanto mais variadas e extraordinárias forem as situações que elas contam, mais ampliarão a gama de abordagens possíveis para os problemas que nos afligem. Um bom acervo de narrativas é como uma boa caixa de ferramentas [...]. (p. 303)

A professora, para dar conta da alfabetização das crianças, foi fazendo uso das ferramentas de diferentes autores; lendo e recontando com as crianças, foi percebendo que contar histórias lhe permitia ressignificar suas vivências. Sair do comprometedor de suas vilas e entrar no sonho de cada autor, escritor, poeta e narrador. Muito mais do que isso, suscitava o imaginário e, com ele, a possibilidade de elaborar e acomodar sentimentos que faziam parte das experiências vividas pelas crianças no cotidiano da periferia. De certa forma, foi a curiosidade respondida em relação a tantas perguntas, a possibilidade de encontrar outras ideias para solucionar as questões que surgiam em seu cotidiano, que fizeram com que tais contos virassem grandes viagens. A partir daí, procurava-se levar cada criança a entender como se inventam modos de contação de histórias e, como isso, constituía-se a trama da produção de leitores e escritores.

Um acontecimento marcou muito essas atividades. Foi o caso da menina Flávia, que colabora para nominar e se pensar o título deste artigo. Flávia tinha 6 anos, era menina, preta, pobre e gorda e, portanto, fugia de todos os parâmetros da naturalização dos sujeitosmeninas ou daqueles que têm tudo para dar certo na vida. Naturalmente, ela estaria fadada ao desvio, à anormalidade. Buscando suporte teórico para pensar nessa aluna, observase que, no Brasil, há uma grande produção bibliográfica que nos remete aos estudos da naturalização e generalização do sujeito branco, elencado como "o mais belo", o "melhor"; ou seja, são estudos que versam sobre modos de se ter uma raça, um gênero, uma geração etc. Tais pesquisas (Dornelles, 2007; Souza, 2010) tratam dos infantis que estão sendo constantemente submetidos à normalização de uma etnia ou raça, de uma idade, de um gênero. Contudo, Foucault nos ensina, em seus estudos sobre os "desvios", que estes são importantes, pois nos dão suporte para "determinar os níveis, fixar as especialidades e tornar úteis as diferenças, ajustando-as umas às outras" (Foucault, 1998, p. 154), ordenando-as como verdade.

Entretanto, entendo que as diferenças, mesmo as que aparecem na rotina da classe de 6 anos, precisam ser compreendidas e analisadas para além da tolerância com a pluralidade; são diferenças culturais, raciais ou de gênero, são diferenças que marcam sempre uma diferença, ou seja, são políticas, permeáveis, existem independentemente de serem ou não aceitas ou que algum poder as nomeie como aceitáveis ou "normais".

Buscar teorizações acerca dos estudos da diferença, da diversidade e da subjetividade permitiu que pudéssemos dar visibilidades a elas na sala de aula e entender que estas não são essencializadas, cristalizadas e naturalizadas e, por não serem fixas, estáveis, únicas e permanentes, não têm este caráter essencial, mas são efeito de um processo de produção, de uma relação. Flávia, em suas "diferenças", era constituída como "sujeito infame" na sala de aula, pois não era loira, nem magra, não tinha a roupa fashion, o brinquedo "de verdade", e sim seu cover, e muito menos era branca.

Todavia, ao se admitir que o poder produz saber, que o poder e o saber estão diretamente implicados, que supõem ou constituem, ao mesmo tempo, relações de poder, essas relações de "poder-saber" não devem então ser analisadas a partir de um sujeito de conhecimento que seria livre ou não em relação ao sistema de poder; foi preciso considerar, ao contrário, que o sujeito que conhece, os objetos a conhecer e as modalidades de conhecimentos são outros tantos efeitos dessas 
implicações fundamentais do poder-saber e de suas transformações históricas. Ou melhor, isto nos fez aprender que não é a atividade do sujeito do conhecimento que produziria um saber, útil ou arredio ao poder, mas o saber-poder, os processos e as lutas que $o$ atravessam e que o constituem que determinavam as formas e os campos possiveis de conhecimento na sala de 6 anos.

As lutas e as forças ali constituídas impeliram Flávia a resolver suas muitas questões de como levar a história lida para a escola. Sua mãe dizia que não tinha tempo para deixar as lidas da casa e ler para a menina. Contou que os livros que tinha em casa eram da época em que seu marido estudava, e que Flavia iria usá-los quando soubesse ler. Mas Flávia encontrou no pai a saída! Todas as noites esperava sua volta para casa (seu pai era segurança em uma fábrica), aguardando ansiosa a leitura do livro. Chegava à escola entusiasmada, contando o que o pai havia lido. Este jogo de leitura cada vez mais se evidenciava na sala, pois a menina lia para o grupo o que o pai havia contado na noite anterior. Flávia nos dizia que eles se deitavam juntos, e o pai lia a história; depois ele passou a contar e a escrever com ela as histórias de sua infância, das suas brincadeiras, travessuras e castigos.

Este ato prazeroso de leitura, constituído por pai e filha, nos mostra aquilo que sugere Kaercher (2010):

[...] o nosso desejo de vê-los lendo faz com que percamos às vezes uma energia incrível de criação que acompanha o processo de tornar-se leitor: naqueles instantes de adivinhação, em que a criança que ainda não lê (no sentido estrito do termo) se dedica à maravilhosa aventura de pensar "o que poderá ser” em cada história, embalagem, placa, imagem, brinquedo [...]. (p. 55)

Ou seja, seu pai transformou esse ato em prazer de constituir uma filha leitora, desejante de ouvir aquela história dos livros e de muitas outras que iriam compor juntos, mesmo que à noite. Aos poucos, em sala de aula, juntaramse às brincadeiras de Flávia as atividades com letras, palavras, histórias, pois ela sempre pedia que se escrevessem na aula as palavras que estava descobrindo com o pai.

No decorrer do tempo, um mundo alfabetizador foi se construindo na sala de aula. Um dia, a professora me disse: "A Flávia está lendo!”. Esta era a confirmação de alguns modos de se alfabetizar que se propunham às crianças de 6 anos, ou seja, não era o Alfa e Beto, ou o Seninha ou o GEEMPA, era a nossa ação e envolvimento com a leitura e a escrita que estavam produzindo na sala de aula nossos primeiros leitores. Flávia era a nossa analfabetadesviante. Flávia passou a ser A FLÁVIA pelos outros alunos, passou a ser a menina que lia para os colegas.

\section{Constituindo-se como alfabetizandos...}

Esta cartografia de produção de leitores foi sendo traçada na aula com as crianças. Foi tudo isso a nossa prática, o nosso jogo de leitura-escrita em que Flávia e todas as crianças iam cruzando a linha feiticeira que traçavam em seus mapas de alfabetismos e de letramentos, e isto estávamos aprendendo a partir da Flávia. Ela havia constituído o seu modo de se alfabetizar, o seu tempo para se alfabetizar, o seu prazer e o destaque na sala de aula por ser alguém que havia descoberto a leitura no grupo. De algum modo, exercíamos o que nos instigava Kaercher (2010), ou seja, acolhíamos os instantes de magia e aproveitávamos para instigar nossas crianças quanto às possibilidades de leitura. Jogando, brincando e curtindo com elas as múltiplas possibilidades de se ler um texto, de se ler o mundo, ou melhor, de nos tornamos curiosos e desejosos da leitura.

Daí o paradoxo: não usávamos métodos, ou, como afirma Trindade (2010), tínhamos o nosso método. Aliás, cabe aqui um parêntese que não se pretende denuncista, mas que nos leva a pensar e a problematizar. Grande é o contingente 
de alfabetizadores que estão sendo expulsos das classes de alfabetização do primeiro ano de 6 anos. Alguns por não preencherem as muitas cartilhas que os acompanham; outros porque ousam cruzar a linha feiticeira e produzir com seu grupo o seu processo de alfabetização. No caso da escola pesquisada, a professora achou necessário estranhar os efeitos produzidos pelas práticas discursivas de sua sala de aula no que diz respeito à fabricação dos professores e, consequentemente, dos alunos a ela afetos. Ousou investigar que estas práticas se tecem sobre fios culturais que se tramam na vida, no cotidiano, nas salas de casas, nos quartos de dormir, na escola, nas pedagogias, didáticas e metodologias construídas também com as crianças, mesmo que fazendo uso de tais materiais.

Contudo, quando ela olhou com estranhamento os discursos que produziam determinados sujeitos, e que, portanto, produziam determinadas práticas e não outras, o convite foi para que saísse da turma. Ou melhor, a professora foi convidada, no ano seguinte, a sair da turma de primeiro ano de 6 anos. Teve que abandonar seu grupo, pois a estatística da escola seria prejudicada por não cumprir a dita cartilha das empresas.

Quando ousou estranhar o que é comum e natural nas aulas que versam sobre alfabetização de crianças de 6 anos, ou seja, estranhar o modo de tratar desse processo, entendendo que este só era possível quando se tramava com a descoberta do mágico da literatura infantil, a professora foi punida. Quando ousou estranhar o que é falado, tratado, narrado e contado, quando ousou cruzar a linha feiticeira de Deleuze (1992) e estranhar os modos de se constituir sujeitos alfabetizandos de 6 anos, foi convidada a se retirar. Talvez porque ela não entraria na estatística por não preencher as muitas fichas, talvez porque naquela sala já se falava sobre contos do mundo, inclusive os africanos, os indígenas, os da Luíza down, os das meninas que gostavam de jogar futebol, os inventados e escritos pelo grupo, todos eles já estavam em nossa sala de aula.

Talvez porque o gráfico apresentado no final de cada avaliação é impossível numa aula de crianças que se lembram das histórias ouvidas embaixo do boabá, metaforizando o quarto de infância de Flávia, onde sua alfabetização foi produzida. A estatística não considera como ela se constitui como leitora na hora de dormir, ouvindo a cantata de seu pai e levando-a às crianças de seu grupo. Nesse quarto ou na nossa sala transformada em quarto de histórias, cruzavam-se histórias fantásticas de heróis, mendigos, ricos, princesas, reis e garotos muito pobres, meninas muito ricas que moravam em castelos e palácios reais. Nelas circulavam verdades sobre como as crianças deveriam se comportar para não perderem seus pais, deveriam estar atentas às maldades do mundo, aos monstros dos grandes mares, ao feitiço das florestas de Hobin Hood, nas aventuras de Dom Quixote, na esperança de que todo patinho feio um dia se transformará num grande cisne real. Isso havia acontecido com Flávia, a princesa-leitora que trazia para o grupo suas imagens, sons, palavras e linguagens, em que se produziam de algum modo crianças amantes de livros, crianças de 6 anos que se constituíam como leitores e escritores.

Contudo, há que se olhar para as escolasempresa ou as alfabetizações-estatísticas como a realizada nesta escola. Elas desconsideraram o fato de que, numa classe de alfabetização de 6 anos, fosse possível ouvir histórias diferentes daquelas propostas pela alfabetização do livro didático. A professora foi punida porque ousou cruzar a linha e romper a regra que diz que um bom professor alfabetizador é aquele que sabe selecionar, de acordo com a faixa etária, a melhor história, o melhor texto e, consequentemente, o melhor método de alfabetização para o seu grupo.

Entende-se que a alfabetização apenas desse modo (livros selecionados pelo professor e de acordo com a faixa etária) acabou pedagogizando e, muitas vezes, maculando o prazer de descobrir letras, palavras, contos, ouvir e contar histórias, e mesmo de poder trazer para o grupo memórias de momentos que antecedem o sono e os sonhos infantis.

A professora resolveu problematizar talvez aquilo que lhe tenha sido mais caro na educação 
dos infantis, ou seja, a possibilidade de construir leitores e escritores trazendo à memória seus momentos de ouvir e contar histórias com as crianças. Trazer imagens, reportar-se no tempo, ouvir velhos sons, cantar antigas canções, ouvir vozes de mães, bruxas, soldados, árvores e pássaros. Rememorar o que lhes estava sendo apresentado no mundo mágico dos livros na sala de aula.

A professora resolveu problematizar o modo pelo qual aparece, na escola, a literatura que trata de contos e lendas, a literatura que trata de heróis que fogem do mito europeu, para trabalhar mitos, deuses, heróis brasileiros, africanos, mexicanos etc. Tratar do lobisomem e da Iemanjá, tratar da antropofagia brasileira dos nossos indígenas. E por isso foi convidada a se retirar. Talvez muitas outras se encontrem neste relato, tantas outras que enfeitiçavam com suas histórias a sala de aula de 6 anos.

A lenda pan-óptica do grande olho vigilante do Argos Panopticon serve para a análise das práticas que percorrem tais programas, visto que a norma ou pan-optismo dos mesmos dizem respeito ao controle e produção do ensino e de conhecimentos de professores, alunos e comunidade. Produz, de algum modo, uma "vontade de verdade", de forma a mostrar como tais verdades fazem parte de um compacto conjunto de estratégias e enunciados pedagógicos, comportamentais, de políticas de gerenciamento e de economia. Tais enunciados talvez mostrem como a produção do aluno cidadão passa pela construção da higiene moral e individualizante tão bem inserida na escola moderna.

Talvez isso faça parte da nova ordem na qual Deleuze (1992) nos chama a atenção sobre a escola-empresa, ao dizer:

0 que conta é que estamos no início de alguma coisa. [...]. No regime de escolas: as formas de controle contínuo, avaliação contínua, e a ação da formação permanente sobre a escola, o abandono correspondente de qualquer pesquisa na Universidade, a introdução da "empresa" em todos os níveis de escolaridade (p. 229).
Acho que esta referência nos aponta como o autor nos dá pistas para que se pensem os programas brasileiros de educação e alfabetização de crianças de 6 anos.

Ou seja, nessa turma, não se usou 0 Método especial, e sim, foi se compondo com o grupo aquilo que já se fazia na educação infantil, ou melhor, se pensava sobre modos de trabalhar ludicamente a leitura e a escrita em nossa aula. A avaliação não precisava ser grafada em "escadas de aprendizagens" expostas nas salas e vigiadas pela secretaria nas visitas de controle ao projeto, para depois transformá-las em tabelas de metas e perspectivas de alfabetização. Estas escadas de aprendizagem expostas na sala, revisadas por supervisores, nada mais eram do que a possibilidade de as crianças poderem acompanhar sua construção como alfabetizandos. Mas se entende, contudo, como um modo de controle da aprendizagem e do trabalho do professor, visto que cotidianamente era preciso revelar para as crianças, professores e pais quem estava ou não atingindo o padrão de alfabetização esperado. Será que algum adulto vem perguntando sobre o que as crianças sentem com seu nome nessa escada?

\section{Optando por continuar com alfabetizações-desviantes}

Não é possível caminhar para o fechamento deste artigo sem pensar no brincar, pensar na criança e em suas possibilidades de alfabetização que se deem no desvio, à margem, na superfície, no devir, ou seja, na opção da constituição de alfabetizandos-desviantes. Por muito tempo, ser criança, dentro de um ideário da modernidade ocidental, era ser um ser brincante, e o brincar infantil foi considerado algo natural, prazeroso, neutro, desinteressado e fazendo parte da "essência" infantil, por isso mesmo "livre" de qualquer interesse ou imposição cultural, passando a ser utilizado como possibilidade para estimular o desenvolvimento físico, mental, social e intelectual de crianças. Os documentos, como vimos, até defendem o brincar. Olhando sua historicidade na 
educação das crianças, observa-se que eles se baseavam, principalmente, nas teorias psicológicas para dizer da importância do brincar e do brinquedo, até então concebida "pelo fato de que seriam inerentes à 'natureza infantil', natureza esta concebida inicialmente, nestas teorias, como de ordem biológica e mais recentemente, como caráter social” (Bujes, 2000, p. 208). Contudo, também sobre o brincar na escola observa-se que o efeito do poder sobre os infantis se exerce não só sobre os conhecimentos produzidos a respeito das crianças, mas também sobre os modos de se inventar sua vida, sua conduta, sua cotidianidade e, consequentemente, seus brinquedos e sua forma de brincar. Portanto, os saberes e poderes que são fabricados, para que se governem os infantis são também atravessados por práticas discursivas que fazem parte da mídia, da publicidade, das indústrias de entretenimento, das legislações que os gerenciam, ou seja, das estratégias de governamento não só dos adultos, mas também das crianças.

Ter um tempo para brincar era garantido para as crianças de 0 a 6 anos, o que me leva a questionar: qual o efeito dessa pedagogização, dessa racionalidade que vem reduzindo o tempo para brincar e de ser criança de 6 anos? Que infância é essa que estamos produzindo? Isso é bom para quem? São questões que precisam ser pensadas quando queremos entender a educação dos infantis ante os desafios colocados pela extensão do ensino fundamental para nove anos.

Peço auxílio a Xavier (2006), quando de sua análise sobre organização escolar, planejamento pedagógico e disciplina. Ela nos ensina e nos alerta que a vida das crianças vai mudando paulatinamente com a saída da educação infantil e o ingresso nas séries posteriores. Sobre a rotina e o planejamento nas classes de primeiros anos, a autora questiona se os professores estão sendo informados de como o tempo e o espaço, os saberes, os desejos, a curiosidade e, principalmente, a ludicidade estão diminuindo.

0 cotidiano do aluno, tão presente na rotina da Educação Infantil, principalmente na pro- posta das rodinhas diárias vai, paulatinamente, perdendo espaço nas séries subsequentes. A partir da primeira série, a vida do aluno - seus saberes, seus desejos, suas curiosidades - fica na porta da escola e da sala de aula. (Xavier, 2006, p. 35)

A autora ajuda a perguntar e tenta achar respostas sobre como se pode construir, numa turma de 6 anos, um modo diferente de pensar a criança alfabetizanda. Muitas vezes, os projetos que se realizam nas turmas de alfabetização são apenas paliativos para o confınamento e a pedagogização dessas crianças. Como também os professores estão se constituindo como professores que não têm mais tempo para brincar com as crianças. Certamente por terem centrado o foco nas aprendizagens, nos conteúdos necessários à alfabetização.

Assim, capturados pelos projetos institucionais de alfabetização e não pelas crianças, vão diminuindo o tempo e o espaço para brincar. $\mathrm{Ou}$ melhor, vão permitindo que a lógica da educação maior, apontada pela planificação presente nos Planos de Educação, nas Diretrizes ou Orientações Curriculares, nos projetos político-pedagógicos, tome conta de seu projeto-criançar-alfabetizar. É o que nos faz pensar Gallo (2002), quando trata da desterritorialização como um dos processos educativos em que as "políticas, os parâmetros, as diretrizes da educação maior estão sempre a nos ensinar. A educação maior procura construir-se como uma imensa máquina de controle, uma máquina de subjetivação, de produção de indivíduos em série" (p. 174).

Olhando para as salas de aula de primeiro ano, observa-se, nesse processo de inclusão das crianças de 6 anos, a diminuição do tempo para brincar e se expressar. Encontro sentido no que diz Guattari (2008), quando nos mostra a entrada das crianças na escola e o quanto esse período coincide com o da latência ensinado por Freud e se surpreende como este não tenha se dado conta desta coincidência: "esse período coincide com a idade de escolarização, a entrada da criança nos equipamentos produtivos modelizantes, a entrada 
nas línguas dominantes” (p. 115). Ainda, como a criança vai perdendo a sua criatividade:

[...] a criança, que tem capacidades extraordinárias como dança, canto e de desenho, perde em poucos meses toda essa riqueza. Sua criatividade cai numa espécie de grau zero; ela começa a fazer desenhos estereotipados, ela se modeliza segundo as atitudes dominantes. (Guattari, 2008, p. 115)

E era nessa experiência dançante, cantante e desenhante que, em nossa sala de alfabetização de 6 anos, crianças e professoras criavam, perguntavam, discutiam a partir das hipóteses das crianças, e com estas se mobilizavam, facilitavam a construção de meninos e meninas produtores de leitura e escritura. Os alunos, a partir de Flávia, como vimos, foram transformando suas aprendizagens num grande acontecimento: a produção de leitores e escritores. Não foram treinos nem exercícios grafomotores, mas sim uma constante interação com o mundo mágico da leitura, como aponta Kaercher (2010). As crianças foram tomando para si a responsabilidade de apresentar umas às outras, de um modo mágico, os seus livros e, não se contendo em relação ao encantamento que havia "dentro" deles, se deliciavam e nos deliciavam com o "encontro com" eles, fazendo com que nossas aulas, com o mundo da leitura e da escritura, fossem mágicas e se transformassem num acontecimento! E, em meio a magias, desejos e danças, foram produzindo sua alfabetização com tal vitalidade, criação e turbulência, que trouxeram à sala de primeiro ano o prazer de aprender. Sua aprendizagem foi permeada pela alegria da descoberta. E a alegria, como diz Spinoza, é sempre boa, é vida que resiste a forças. Esta alegria é combate, e as crianças podem ser a força a mais das forças. Assim pode ser possivel resistir à arrepiante experiência vivida pelas nossas crianças de periferia. Convido-os ao desvio!

\section{Referências}

BEAUCHAMP, J.; PAGEL, S. D.; NASCIMENTO, A. R. Ensino fundamental de nove anos: orientações para a inclusão da criança de seis anos de idade. $2^{a}$ ed. Brasília: Ministério da Educação, Secretaria de Educação Básica, 2007, p. 97-107.

BRASIL. Conselho Nacional de Educação. Câmara de Educação Básica. Parecer CNE n. 22/98, de 17 de dezembro de 1998. Diretrizes curriculares nacionais para a educação infantil. Brasília, DF, 1998. Disponível em:http://wwwdiretrízes_p0481-500_c. pdf. >. Acesso em 24 jan. 2009.

Constituição 1988. República Federativa do Brasil, 1988. Brasília, DF: Senado Federal, 1988.

BUJES, M. I. Criança e brinquedo: feitos um para o outro. In: COSTA, M. V. Estudos culturais: mídia, brinquedo, biologia, literatura, cinema... Porto Alegre: Universidade/UFRGS, 2000.

CORSO, D., CORSO, M. Fadas no divã: psicanálise nas histórias infantis. Porto Alegre: Artmed, 2006. 
DELEUZE, G. Conversações. Rio de Janeiro: 34, 1992.

DORNELLES, L. V. Os brinquedos na mídia e na publicidade: estratégias de produção dos infantis. In: MORIGI, V. (org.). Mídia e representações da infância: narrativas contemporâneas. Curitiba: Champagnat, 2007.

. A produção de sujeitos alfabetizados. Brincando com as palavras e com os livros na escolarização inicial. In: AlfabeLetrar: fundamentos e práticas. Porto Alegre: Mediação, 2010.

FISCHER, R. M. Sobre o dispositivo pedagógico da mídia: estratégias de interpelação do sujeito. Porto Alegre: Universidade Federal do Rio Grande do Sul, Faculdade de Educação PPGEDU, 2001 (digitado).

FOUCAULT, M. Microfísica do poder. Rio de Janeiro: Graal, 1998.

A verdade e as formas jurídicas. Rio de Janeiro: Nau, 1999.

Arqueologia das ciências e história dos sistemas de pensamento [Ditos e Escritos; III]. Rio de Janeiro: Forense Universitária, 2000.

GALLO, S. Em torno de uma educação menor. Educação e Realidade, Porto Alegre, v. 27, nº 02, p. 169-178, 2002.

GUATTARI, F.; ROLNIK, S. Micropolítica: cartografia do desejo. Rio de Janeiro: Vozes, 2008.

HÖLDERLIN, F. Poemas. Lisboa: Relógio d'água, 1991.

JÓDAR, F.; GÓMEZ, L. Devir-criança: experimentar e explorar outra educação. Educação e Realidade, v. 27 (2), p. 31-45, 2002.

KAERCHER, G. E. P. S. Brincando com as palavras e com os livros na escolarização inicial. In: AlfabeLetrar: fundamentos e práticas. Porto Alegre: Mediação, 2010.

PAGEL, S. D.; NASCIMENTO, A. R. Ensino fundamental de nove anos: orientações para a inclusão da criança de seis anos de idade. $2^{\mathrm{a}}$ ed. Brasília: Ministério da Educação, Secretaria de Educação Básica, 2007, p. 13-23.

RIFFEL, M. J. A ordem da "humanização do parto" na educação da vida. Porto Alegre, 2005. Tese (doutorado). Universidade Federal do Rio Grande do Sul. Faculdade de Educação. Programa de Pós-graduação em Educação.

SANTAIANA, R. S. + 1 ano é fundamental: práticas de governamento dos sujeitos infantis nos discursos do ensino fundamental de nove anos. Porto Alegre, 2008. Dissertação (mestrado). Universidade Federal do Rio Grande do Sul. Faculdade de Educação. Programa de Pós-graduação em Educação.

SCHINEIDER, S. 0 projeto-piloto de alfabetização do Rio Grande do Sul: um olhar estranhamento sobre seus materiais didáticos. Porto Alegre, 2009. Dissertação (mestrado). Universidade Federal do Rio Grande do Sul. Faculdade de Educação. Programa de Pós-graduação em Educação.

SOUZA, F. M. Revirando malas: entre histórias de bonecas e crianças. Porto Alegre, 2010. Dissertação (mestrado). Universidade Federal do Rio Grande do Sul. Faculdade de Educação. Programa de Pós-graduação em Educação. 
SPINK, M. J. Os contornos do risco na modernidade reflexiva: contribuições da psicologia social. In: Revista da Associação Brasileira de Psicologia Social - ABRAPSO, v. 12, nº. 12, jan./dez. 2000.

TRINDADE, I. Não há como alfabetizar sem método. In: AlfabeLetrar: fundamentos e práticas. Porto Alegre: Mediação, 2010.

XAVIER, M. L. (org.). Disciplina na escola: enfrentamentos e reflexões. $2^{a}$ ed. Porto Alegre: Mediação, 2006.

Recebido em: 27.09.2010

Aprovado em: 19.11.2010

Leni Vieira Dornelles é pedagoga. Professora associada do Departamento de Estudos Especializados da Faculdade de Educação na Universidade Federal do Rio Grande do Sul. Membro do GEIN (Grupo de Estudos em Educação Infantil) e da Comissão de Pós-graduação. 